Anales de Geografía de la Universidad Complutense ISSN: 0211-9803

http://dx.doi.org/10.5209/AGUC. 62486

\title{
La desigualdad en el reparto de la tierra en Colombia: Obstáculo principal para una paz duradera y democrática
}

\author{
José Antonio Segrelles Serrano ${ }^{1}$ \\ Recibido: 29 de mayo del 2017/ Enviado a evaluar: 21 de julio del 2017/ Aceptado: 18 de octubre del 2018
}

\begin{abstract}
Resumen. La desigualdad en el reparto de la tierra en Colombia y la consiguiente pobreza rural es la causa principal del conflicto armado que ha vivido el país durante más de cincuenta años. La concentración de la tierra en pocas manos, el poder de la agroindustria y los ganaderos, así como la preeminencia de una agricultura orientada más a la exportación que al consumo interno, hacen necesaria una reforma agraria que vaya más allá de la mera redistribución de tierras, pues el campesinado necesita una democratización del campo mediante el acceso a los insumos, al crédito y a la asistencia técnica, además de infraestructuras, educación, vivienda y sanidad. Las nuevas legislaciones agropecuarias y rurales, nacidas en el seno del proceso de paz y con el fin de gestionar la etapa posterior al conflicto armado, son incompletas, tienen muchas limitaciones y no modifican sustancialmente el origen de todos los problemas: la estructura de la propiedad de la tierra.
\end{abstract}

Palabras clave: concentración de la tierra; proceso de paz; postconflicto; Colombia.

\section{[en] Inequality in the distribution of land in Colombia: Main obstacle to a lasting and democratic peace}

\begin{abstract}
The unequal distribution of land ownership in Colombia and consequent rural poverty is the main cause of the armed conflict that has beset the country for over fifty years. The concentration of land ownership in the hands of the few, the power wielded by agribusiness and farmers and the predominance of a farming system aimed more at export than at domestic consumption, all urge a reform that goes beyond mere land redistribution: land ownership must be democratised by providing small farmers with access to supplies, credit and technical assistance, as well as infrastructures, education, housing and health. The new agricultural and rural legislation brought in during the peace process to help usher in the post-conflict era is incomplete, presents many limitations and does not substantially address the root of all the problems: the land ownership structure.
\end{abstract}

Key words: concentration of land ownership; peace process; post-conflict; Colombia.

1 Departamento de Geografía Humana. Universidad de Alicante

E-mail: jasegrelles@ua.es 
[fr] L'inégalité dans la répartition des terres en Colombie: principal obstacle à une paix durable et démocratique

Résumé. L'inégalité dans la répartition de la terre en Colombie et la pauvreté rurale qui en découle est la cause principale du conflit armé qui a secoué le pays pendant plus de cinquante ans. La concentration de la terre aux mains d'une minorité infime, le pouvoir de l'agro-industrie et des éleveurs, ainsi que la prédominance d'une agriculture tournée vers l'exportation plutôt que vers la consommation intérieure, rendent nécessaire une réforme agraire qui aille au-delà d'une simple redistribution des terres ; en effet, les paysans nécessitent d'une démocratisation de la campagne par le biais de l'accès aux intrants, au crédit et à l'assistance technique, en plus d'infrastructures telles que l'éducation, le logement et la santé. Les nouvelles législations sur l'agriculture et l'élevage, engendrées dans le cadre du processus de paix et dans l'objet de gérer l'étape postérieure au conflit armé, sont incomplètes, elles se heurtent à de nombreuses limitations et elles ne modifient pas de manière substantielle l'origine de tous les problèmes : la structure de la propriété de la terre.

Mots clés: concentration de la terre; processus de paix; post-conflit; Colombie.

Cómo citar. Segrelles Serrano, J.A. (2018): La desigualdad en el reparto de la tierra en Colombia: Obstáculo principal para una paz duradera y democrática. Anales de Geografía de la Universidad Complutense, 38(2), 409-433.

Sumario. 1. Introducción. 2. La concentración de la propiedad de la tierra. 3. El uso de la tierra. 3.1. Aprovechamientos del agro colombiano: exportación frente a consumo interno. 3.2. La producción de agrocombustibles y la ganadería extensiva. 4. Conclusiones. 5. Bibliografía.

\section{Introducción}

La lucha por la tierra ha sido el origen de múltiples antagonismos sociales, conflictos armados y guerras civiles en la mayoría de los países de América Latina. Esto ha sido así desde el mismo momento de sus independencias como Estados soberanos en el siglo XIX y también durante el transcurso del siglo XX. Incluso ya casi se han alcanzado dos décadas del siglo XXI y el problema de la tierra sigue vigente, como así lo demuestra el hecho de que la distribución de la tierra fuera el primer asunto tratado en las negociaciones de paz entre el Gobierno de Colombia y la guerrilla de las Fuerzas Armadas Revolucionarias de Colombia (FARC) en el mes de agosto de 2016.También fue el primer punto en el Acuerdo Final para la Terminación del Conflicto y la Construcción de una Paz Estable y Duradera signado el 24 de noviembre de 2016 en La Habana entre ambas partes. Dicho punto recibió el siguiente título: "Hacia un Nuevo Campo Colombiano: Reforma Rural Integral"2.

${ }^{2}$ Acuerdo Final para la Terminación del Conflicto y la Construcción de una Paz Estable y Duradera. Disponible en: <https://www.mesadeconversaciones.com.co/sites/default/files/241480106030.11-1480106030.2016nuevoacuerdofinal-1480106030.pdf>. [Consulta: 2 de febrero de 2017]. 
Buena muestra de la importancia económica, social, política, ambiental y cultural que tiene la propiedad de la tierra, la tenencia de la misma y su secular reparto desigual en Colombia es la proliferación de estudios que sobre esta cuestión han ayudado a aumentar el acervo científico e intelectual del país desde comienzos del siglo XX y hasta nuestros días, pues son muchos los autores que de una u otra forma han analizado este fenómeno de capital importancia (Martínez, 1938; Mendoza, 1942; Pérez Ramírez, 1959; Mendieta, 1960; Zulueta, 1973; Fals, 1979; Lorente, 1984; Reyes, 1988; FAO-CEGA, 1994; Machado, 1998; Díaz, 2002; Offstein, 2005; Asistencia Técnica Internacional del Tercer Laboratorio de Paz, 2011; Instituto Geográfico “Agustín Codazzi”, 2012; Suescún, 2013; OCDE, 2015; UPRA, 2015). Este tema ha generado en Colombia un patrimonio cultural y científico que no está ni mucho menos agotado, como puede comprobarse en los estudios publicados durante los últimos años.

Pese a todo, Colombia ha avanzado en el siglo XXI sin resolver de manera definitiva los problemas estructurales de su agro. Esto obstaculiza el acceso de los agricultores a los recursos productivos, con el consiguiente retraso del sector agrícola y ganadero en cuanto a su desarrollo. Durante varias décadas se han intentado culminar diversas reformas agrarias que siempre han resultado insuficientes, han estado mal dirigidas e incluso han sido inoperantes para el desarrollo del mercado de la tierra y la mejora de las condiciones de vida de los campesinos y los habitantes rurales. Esta situación, muy común en el conjunto de la región latinoamericana (Guereña, 2016), se revela especialmente problemática y violenta en Colombia, nación que pasa por ser una de las democracias más sólidas de América Latina, con sólo una corta dictadura en la década de los años cincuenta del siglo pasado. No obstante, los colombianos han vivido un conflicto armado, el más antiguo de todo el continente, que ha dejado un reguero interminable de personas asesinadas y desaparecidas y una inequidad socioeconómica crónica.

En efecto, en el caso colombiano "la modalidad de ocupación espacial histórica del territorio, los procesos de colonización agraria con sus asentamientos poblacionales y la ausencia del Estado, han conllevado a una alta concentración de la propiedad con sociedades regionales frágiles; configurando una realidad rural fuente de rentas privilegiadas, de escenarios de conflictos y de violencias", según indica el estudio realizado por la Asistencia Técnica Internacional del Tercer Laboratorio de Paz (2011: 6).

La senda hacia la paz y la democracia pasa indefectiblemente por recuperar la vida agraria y garantizar el desarrollo rural integral, pues el campo ha estado en el centro del conflicto armado desde el principio. Han sido millones las personas que se vieron obligadas a abandonar sus tierras para escapar de la violencia. En ciertas zonas estratégicas, el desplazamiento ha afectado a comunidades rurales enteras. De este modo perdieron tanto sus medios de vida como su cultura y las raíces que los vinculaban a una sabiduría tradicional y a unas prácticas agropecuarias que siempre han representado sus señas de identidad, la garantía de un medio rural vivo y la soberanía alimentaria de los pueblos. 
El objetivo principal se centra en el análisis de los rasgos más característicos de la agricultura y el medio rural en Colombia, que son precisamente los que han contribuido con mayor intensidad a la generalizada pobreza existente en los espacios no urbanos del país y cuya permanencia secular constituye el origen y continuidad del sangriento conflicto armado que ha asolado a esta nación durante decenios. En la actualidad, ante una nueva oportunidad que proporciona la historia para conseguir una paz definitiva en el país, no se puede ser completamente optimista acerca del cumplimiento de todas las iniciativas que se pretende poner en marcha para reparar a las víctimas del conflicto, restituir las tierras despojadas, conseguir un desarrollo rural integral y modernizar el campo ayudando a la productividad y rentabilidad de las pequeñas explotaciones campesinas. No han sido pocos los intentos frustrados en este sentido desde hace un siglo. Este puede ser otro intento fallido más, que durante un tiempo ocupe a los políticos y agentes sociales, elaborando documentos y promulgando leyes, y después quede en un mero papel mojado. Puede que la guerrilla, los paramilitares, el ejército y los narcotraficantes cesen sus hostilidades, pero si la estructura de la propiedad de la tierra no se modifica, si los grandes terratenientes no pagan impuestos o hacen rentables sus improductivas haciendas, si no se apoya y financia de forma expresa al campesinado y no se termina con la histórica connivencia entre el latifundio, la agroindustria y el poder político, el problema agrorrural colombiano siempre estará latente. Estos aspectos constituyen la hipótesis de partida de esta reflexión.

\section{La concentración de la propiedad de la tierra}

El injusto desequilibrio en la propiedad de la tierra es una característica secular de los países de América Latina que la revolución verde contribuyó a profundizar. Respecto al caso concreto de Brasil, pero extensible al resto de la región latinoamericana, Colombia inclusive, A. P. Guimarâes (1979) decía que el futuro de la agricultura del país dependería de la capacidad que tuvieran las fuerzas sociales mayoritarias en el campo para exigir y obtener una transformación sin paliativos de la tradicional política de concentración de la propiedad, la producción y la renta, que venía, y todavía viene, siendo aplicada secularmente en el agro brasileño. Idénticos razonamientos se pueden plantear por lo que respecta a Colombia.

El avance de la liberalización de la agricultura en la mayoría de los países de Latinoamérica ha supuesto un agravamiento de los conflictos rurales tradicionales, ya que la apertura delos mercados nacionales representa un aumento notable de las importaciones de productos agroalimentarios (Ramiro, González y Pulido, 2007: 4647), hecho que intensifica las presiones económicas sobre los pequeños campesinos. Al mismo tiempo, el crédito se ha ido concentrando, igual que la propiedad de la tierra, en los grandes hacendados y complejos agroindustriales. Esta falta de apoyo del Estado al sector agropecuario sin duda tiene su origen en las diferentes crisis sufridas durante las décadas de los años ochenta y noventa del siglo XX, pues a cambio de préstamos multimillonarios el FMI instó a las diversas autoridades 
nacionales para que profundizaran las medidas neoliberales que ya se estaban llevando a cabo desde varios lustros atrás.

Pese al abundante aparato legislativo existente, la práctica inhibición de los Gobiernos en materia agropecuaria, la búsqueda de economías de escala por parte de los complejos agroindustriales mediante el aumento de la productividad, los rendimientos y el tamaño físico de las explotaciones, así como las necesidades dimensionales de la base agraria del modelo agroexportador, son factores que fomentan la concentración de la propiedad de la tierra. A esta situación propia de Colombia y otros países latinoamericanos, por la que unos pocos acumulan mucha tierra y una legión de agricultores pequeños y medianos apenas tiene superficie para sobrevivir, no es ajena la "megalomanía rural" de las oligarquías, que desde siempre han identificado la proyección social y el prestigio político con la posesión de grandes extensiones de tierra, aunque ésta no sea su principal fuente de ingresos ni les inquiete demasiado su explotación económica. Es de una lógica cruel que aquellos que poseen mucha tierra, y no dependen de ella para sobrevivir, se preocupen muy poco de hacerla producir, utilizándola fundamentalmente para la especulación, como reserva de valor o como simple instrumento de poder.

La propiedad de la tierra en Colombia se encuentra fuertemente concentrada. Las propiedades menores de 10 hectáreas representan el 78,03\% del total y suponen sólo el 5,95\% de toda la superficie agrícola, agropecuaria, ganadera, forestal $\mathrm{y}$ agroindustrial del país. El 80\% de los pequeños agricultores del país tienen menos de una Unidad Agrícola Familiar (UAF), es decir, son microfundistas. Por el contrario, las propiedades superiores a 1.000 hectáreas representan únicamente el $0,19 \%$ y concentran el 53,97\% de todas las tierras. Sin embargo, lo más llamativo es que las 275 propiedades mayores de 10.000 hectáreas del país suponen el $0,02 \%$ del total y absorben nada menos que el 40,89\% de las tierras. Como indica E. Sarmiento (2015), la concentración del sector agropecuario es alarmante porque la estructura de la propiedad de la tierra no se ha modificado en absoluto en dos siglos. Este sector constituye una forma de atesorar la riqueza, aislarla de la economía y obtener grandes beneficios de valorización (Sarmiento, 2015: 1).

El proceso de concentración de la tierra no ha cesado durante las últimas décadas. Hay que tener en cuenta que los latifundios mayores de 1.000 hectáreas poseían el $26,6 \%$ de la superficie agropecuaria del país en 1992, mientras que los minifundios, es decir, con dimensiones menores de 10 hectáreas, ejercían el dominio sobre el 8,8\% de las tierras en la misma fecha. A finales de esta misma década, el Instituto Geográfico "Agustín Codazzi" presentó una nueva distribución de la propiedad de la tierra en Colombia: el $67 \%$ de los propietarios (2,3 millones de personas) poseía cada uno de ellos una explotación menor de cinco hectáreas, es decir, sólo el 3\% de la superficie. Por el contrario, 2.055 latifundistas, dueños de fincas superiores a 2.000 hectáreas que significan un ridículo $0,06 \%$ de todos los propietarios del país, acaparaban el 51,5\% de la superficie agropecuaria colombiana. Aunque el número de grandes propietarios ha disminuido, la tierra se ha concentrado en menos manos. Es decir, menos latifundios, pero con mayores dimensiones superficiales. Este cruel 
contraste es lo que ha explicado la larga pervivencia de la violencia en las zonas rurales del país, según J. Vásquez (2002: 178).

Este claro proceso de reconcentración de la tierra no sólo lo han llevado a cabo los grandes terratenientes, sino que a partir de los decenios de los años ochenta y noventa del siglo pasado entró en escena un nuevo actor que acumuló gran cantidad de tierras en no demasiado tiempo: el narcotráfico. El Departamento Nacional de Planeación $(\mathrm{DNP})^{3}$ estimaba que los narcotraficantes habían comprado tierras, entre los años 1980 y 1995, en el 37\% de los municipios del país. Esta situación supuso la elevación de los niveles de concentración de la propiedad agropecuaria, el desplazamiento de los campesinos desde los frentes de colonización a las ciudades, el aumento del precio de la tierra, la financiación de los paramilitares y la reorientación de los suelos más fértiles hacia la ganadería extensiva, en perjuicio de la agricultura y los bosques (Segrelles y Vásquez, 2012: 295-296). A este respecto se calcula que 6,6 millones de hectáreas fueron despojadas por la violencia de las últimas dos décadas, es decir, el $15 \%$ de la superficie agropecuaria del país ${ }^{4}$.

Según los datos elaborados por la Unidad de Planificación Rural AgropecuariaUPRA (2015), el índice de Gini del conjunto del país es de 0,73, si bien hay diferencias sensibles entre sus departamentos, ya que algunos, como Atlántico o Vaupés, están por debajo de 0,30 , mientras que la mayoría superan el valor de 0,70 , con especial intensidad en Sucre $(0,92)$, Vichada $(0,91)$ o Cauca $(0,89)$. No obstante, otros estudios estiman que el índice de Gini de concentración de tierras es de 0,89 en 2011, cuando en 2005 era de 0,86 (Asistencia Técnica Internacional del Tercer Laboratorio de Paz, 2011). Por su parte, G. Escobar (2016: 3) sostiene que este índice es de 0,88 en 2014, cifra en la que para el año 2011 coincide Arantxa Guereña (2016: 22).

La desequilibrada distribución de la propiedad de la tierra constituye un fenómeno tradicional ya enquistado en la vida rural de Colombia y que no cesa de agravarse con la aplicación de políticas neoliberales. Al amparo de la debilidad del Estado, casi siempre rehén de las potencias centrales, los organismos financieros internacionales y la oligarquía terrateniente local, las grandes propiedades continúan ampliando su extensión por medio de la absorción de los predios menores, fenómeno que muy bien se podría calificar como de "fagocitosis rural".

El instrumento utilizado en mayor medida por los Gobiernos neoliberales para aplicar sus políticas discriminatorias en el agro es el de la financiación selectiva, ya que la extendida idea de que se deja el campo a su suerte, sin protección y sometido a los vaivenes del mercado es cierta a medias. El abandono se produce respecto a la agricultura campesina y a la ausencia de unas políticas que intenten conservar el

\footnotetext{
${ }^{3}$ Organismo creado en 1958 y cuya función principal es la de asesorar el Presidente de la República en el marco de la Constitución de 1991.

${ }^{4}<$ http://www.semana.com/especiales/pilares-tierra/asi-es-la-colombia-rural.html>. [Consulta: 12 de marzo de 2017].
} 
contenido social del medio rural, pero no por lo que atañe a las grandes empresas agroindustriales, competitivas y vinculadas al comercio de exportación, que reciben muchos recursos estatales de tipo financiero y tecnológico. Todo ello provoca un evidente proceso de "descampesinización" porque el pequeño productor, objeto de presiones políticas y económicas continuas, no puede competir con las grandes estructuras agroindustriales en un mercado libre y abandona el cultivo de la tierra y su propiedad agraria.

Según indica D. Tanuro (2011), el capitalismo, como todo modo de producción, se caracteriza por una ley de población específica que en este caso expresa la necesidad de que este sistema productivo disponga de manera permanente de un "ejército de reserva industrial" que se recluta ante todo en las capas campesinas víctimas del agribusiness. Bajo otros modos de producción, en un cierto estadio de desarrollo la sobrepoblación relativa favorecía un alza de la productividad del trabajo. Como había más personas que alimentar, se roturaban nuevos terrenos forestales hasta que los límites de las soluciones extensivas estimularon la invención de nuevas prácticas intensivas que permitían aumentar los rendimientos. El miedo al hambre y a la pobreza estimulaba el crecimiento de la productividad. Con el capitalismo esta relación se invierte, ya que la sobrepoblación relativa ya no conlleva una intensificación de la agricultura, sino que esta segunda motiva la primera. La inmensa mayoría de los millones de individuos que en la actualidad padecen hambre crónica residen en las zonas rurales y serían perfectamente capaces de satisfacer sus necesidades. Sin embargo, existen dos factores que impiden que esto sea una realidad: no tienen acceso a la tierra y la competencia del agrobusiness les aplasta (Tanuro, 2011: 168).

La injusticia del proceso neoliberal en la agricultura, que excluye al pequeño productor, no sólo tiene una raíz social, sino también económica, ya que en algunos estudios, según indica S. Fernández Castillo (2001), se rompe con ciertas ideas productivistas neoclásicas muy arraigadas y se demuestra que las pequeñas propiedades agropecuarias pueden ser tan productivas como las grandes empresas capitalistas del sector, siempre y cuando cuenten con las condiciones adecuadas de comercialización, precios, créditos blandos, transferencia de tecnología, innovación, adquisición de insumos, regadíos o construcción de infraestructuras viarias, hecho que por desgracia no suele ser habitual en la actualidad.

Sin embargo, el productor campesino se encuentra ante dos grandes limitaciones: la falta de tierra y la ausencia de capital. Esto le impide el aumento de su productividad. Y si a ello se añade una forma de producción basada en la subsistencia y la consecución de mínimos excedentes, la conclusión es diáfana: la agricultura campesina es ineficiente y no sabe ni puede responder a las señales del mercado. Sin embargo, estos importantes obstáculos podrían salvarse con una adecuada asesoría técnica e impulsando el fenómeno cooperativo.

El informe de la FAO (2016) sobre El estado mundial de la agricultura y la alimentación sostiene que las explotaciones agrícolas familiares producen alrededor del $80 \%$ de los alimentos del planeta, lo que deviene fundamental para solucionar el problema del hambre, que afecta a más de 800 millones de personas. Estas 
explotaciones familiares son también los custodios del $75 \%$ de todos los recursos agrícolas mundiales $\mathrm{y}$, en consecuencia, resultan vitales para mejorar la sostenibilidad ecológica y de los recursos naturales. La experiencia demuestra que las tierras gestionadas por los agricultores familiares arrojan excelentes rendimientos y producen una mayor proporción de alimentos con relación al porcentaje de tierras que utilizan respecto a los latifundios 5 .

La agricultura familiar afronta un triple reto: aumentar sus rendimientos para satisfacer la seguridad alimentaria y una mejor nutrición, asegurar la sostenibilidad ambiental con el fin de garantizar la protección del planeta y su propia capacidad productiva, e incrementar la productividad y diversificar sus medios de vida para abandonar la pobreza y el hambre. Para lograr estos objetivos el agricultor familiar debe ser capaz de innovar, pero rápidamente surge la pregunta de cómo es posible que innove un campesino pequeño o mediano, descapitalizado y abandonado a su suerte por parte de la inversión y los poderes públicos. Es de todo punto necesario que el Estado colombiano asuma que las dimensiones de las pequeñas explotaciones deberían aumentar, así como elevar su capitalización y erradicar, al mismo tiempo, la crónica ineficacia de las grandes propiedades agropecuarias. Esta tarea, como indica E. Sarmiento (2015), no puede dejarse a la discrecionalidad del mercado, pues el mantenimiento de una estructura agraria de mayor productividad en áreas extensas puede significar el desplazamiento del pequeño productor y el aumento de los niveles de concentración de la tierra (Sarmiento, 2015: 2). La "mano invisible" del mercado suele favorecer a los que más tienen.

Ante el problema secular de la concentración de la tierra en Colombia, la primera reforma agraria importante del país tuvo lugar en $1936^{6}$, precedente de la Ley 136 de 1961, o Ley de Reforma Agraria, impulsada por el Instituto Colombiano de la Reforma Agraria (INCORA) ${ }^{7}$ tras realizar el primer censo agropecuario nacional en los años 1960-1961. Antes de promover las medidas distributivas pertinentes se hacía necesario realizar un análisis de la estructura de la propiedad de la tierra. Dada la elevada concentración de la tierra en pocas manos, diez años después se realizó un segundo censo como forma de equilibrar la entrega de tierras, si bien se avanzó poco e incluso en algunas zonas hubo retrocesos y la propiedad agropecuaria se concentró aún más. Sus limitaciones y deficiencias se intentaron resolver con nuevas leyes,

\footnotetext{
${ }^{5}$ Se calcula que, a pesar de los problemas para acceder a la tierra, el $70 \%$ de los alimentos que se producen en Colombia proviene de los pequeños campesinos. $<$ http://www.semana.com/especiales/pilares-tierra/asi-es-la-colombia-rural.html $>$. [Consulta: 12 de marzo de 2017].

${ }^{6}$ Ley de Tierras o Ley 200 de 1936 del Gobierno de Alfonso López Pumarejo.

${ }^{7}$ En teoría, esta institución del Estado se encarga de promover el acceso a la propiedad rural y su ordenamiento social, ambiental y cultural para propiciar el desarrollo productivo sostenible de la economía campesina, indígena y negra mediante la redistribución democrática de la propiedad, la conformación de empresas básicas agropecuarias y el fomento de los servicios complementarios del desarrollo rural. Fue disuelto en el año 2002 y reemplazado por el Instituto Colombiano de Desarrollo Rural (INCODER).
} 
como por ejemplo la Ley $4^{\text {a }}$ de 1973, del Gobierno de Misael Pastrana Borrero, y la Ley $6^{a}$ de 1975 sobre Aparcería, del Gobierno de Alfonso López Michelsen. Esta última propició el llamado Acuerdo del Chicoral, establecido en el gobierno anterior y que no fue otra cosa que el inicio de la contrarreforma agraria, ya que se tomaron medidas que ante todo favorecían a los grandes terratenientes. Otras iniciativas legislativas en aras de una reforma agraria en Colombia fueron las promovidas por el presidente Belisario Betancur en sus negociaciones de Cese al Fuego, Tregua y Paz con la guerrilla de las FARC en 1982, la Ley 30 de 1988, del presidente Virgilio Barco, y la Ley 160 de 1994, sobre subsidios a la adquisición de tierras, del presidente César Gaviria, en el marco de las recomendaciones del Banco Mundial (Segrelles y Vásquez, 2012: 293-295).

También se han promovido recientemente varias leyes ${ }^{8}$ con diferentes objetivos agrorrurales: adquisición de tierras para la población afectada por los desplazamientos forzosos, adjudicación de tierras baldías, reactivación socioeconómica de las zonas rurales damnificadas por las catástrofes naturales, administración de los bienes incautados al narcotráfico, organización de las cadenas productivas en los sectores forestal y agropecuario, apoyo a las mujeres rurales, gestión y control forestal, consolidación e impulso del desarrollo rural (Segrelles y Vásquez, 2012: 300-308).

Pese a todos estos intentos por conseguir una reforma agraria democrática ${ }^{9}$, acometer el desarrollo rural y paliar el desequilibrio existente en la estructura agraria colombiana, el proceso de concentración de la propiedad de la tierra no ha dejado de intensificarse, lo que representa un lastre para la productividad de su agricultura, un acusado desarraigo campesino, un desarrollo rural deficiente y una dura agresión contra el ambiente y los recursos naturales del país. Con todo, y aun siendo fundamentales estos factores, la consecuencia más dura, prolongada y cruel del desigual reparto de la tierra ha sido durante largas décadas la lucha armada entre los movimientos guerrilleros, las organizaciones paramilitares, los narcotraficantes y el Estado. A este respecto, J. M. Martín Medem no duda en afirmar que el origen del conflicto armado en Colombia radica en la tremenda concentración de la propiedad de la tierra y en el bloqueo de la participación democrática mediante el terrorismo de Estado (Martín, 2016: 298). Es más, sostiene que este conflicto que ha sembrado de violencia el medio rural colombiano lo inició el Estado en 1946 al haber desatado en aquel preciso momento el genocidio premeditado, sistemático y generalizado de los partidarios de Jorge Eliécer Gaitán, quienes avanzaban bajo su liderazgo hacia la conquista del poder (Martín, 2016: 318).

${ }^{8}$ Ley 608 de 2000 (Ley Quimbaya); Ley 731 de 2002; Ley 785 de 2002; Ley 793 de 2002; Ley 811 de 2003; Ley 975 de 2005; Ley 1021 de 2006; Ley 1152 de 2007; Ley de Víctimas y Restitución de Tierras de 2011. Resulta interesante el análisis que realiza Bersarión Gómez Hernández (2011) sobre estas leyes, sobre todo de las más recientes por su importancia para el futuro del proceso de paz.

${ }^{9} \mathrm{Se}$ calcula que durante los últimos 50 años se han titulado 23 millones de hectáreas en Colombia. Sólo el 5,6\% se ha realizado por medio de la reforma agraria. 
Según E. Wiener, citada por G. Escobar (2016), se distinguen, teniendo en cuenta el objetivo de la explotación, cuatro procesos de concentración de la propiedad de la tierra: concentración para fines agrícolas, es decir, producción de alimentos por parte del agribusiness; concentración para la producción de agrocombustibles; concentración para el desarrollo de industrias extractivas; y concentración para fines forestales (Escobar, 2016: 5). Esto significa, en definitiva, que el uso de la tierra y la concentración de la misma se alimentan mutuamente. Determinados aprovechamientos estimulan la concentración de la propiedad agraria en pocas manos, mientras que las grandes haciendas de monocultivo requieren extensas superficies para cumplir sus objetivos comerciales y de productividad. En cualquier caso, el resultado es el despojo de los pequeños y medianos campesinos, el deterioro ambiental y la pérdida de la soberanía alimentaria.

\section{El uso de la tierra}

La utilización de la tierra y la estructura de su propiedad están muy relacionadas con la población activa agraria y su productividad, aunque en el fondo todo ello se encuentra mediatizado por las condiciones que impone el sistema capitalista en su faceta mundializada y neoliberal, que en realidad es la que determina cómo se usa la tierra, cómo se distribuye su propiedad y qué papel representan los trabajadores del campo en el esquema socio-productivo imperante.

Según la opinión de M. Piña (2001), las economías latinoamericanas que han tenido mayor éxito en la aplicación de políticas neoliberales en la agricultura están representadas por Argentina, Chile y Uruguay, países donde existe un extendido dominio del capital en el sector agrario como consecuencia de la debilidad relativa de las unidades campesinas de producción, mientras que por el contrario, en las naciones en las que hay una fuerte presencia campesina, como es el caso de Colombia, la modernización del agro ha sido limitada y, por consiguiente, las políticas neoliberales acentúan en el campo las contradicciones entre el capital, sea nacional o internacional, y el trabajo.

Las cuestiones de la propiedad y el reparto de la tierra han aglutinado de forma tradicional a las poblaciones campesinas de Latinoamérica, ocasionando diversos movimientos reivindicativos y levantamientos populares de gran trascendencia pública en aras de una reforma agraria. Sin embargo, el uso y dedicación de la tierra apenas se ha planteado hasta ahora en términos sociopolíticos, toda vez que la mayoría de los países latinoamericanos está experimentando desde hace algo más de tres lustros una reorganización de sus territorios y aprovechamientos agropecuarios sin precedentes. Dicha reorganización de los espacios y producciones agrícolas, pecuarios y forestales está causada por dos fenómenos muy activos e intensos que en el fondo son la misma cosa y tienen idénticas consecuencias: la difusión generalizada del complejo cereales-carne y la necesidad imperiosa de exportar para poder estar presentes en los circuitos mercantiles internacionales y obtener divisas. Este fenómeno impulsa los cultivos destinados a la exportación y la competencia en los 
mercados internacionales en detrimento de los productos para alimentar a la población local y de la soberanía alimentaria del país.

Es necesario, por lo tanto, que Colombia y el conjunto de América Latina pongan en marcha una verdadera política de reforma agraria que no consista sólo en una mera distribución de tierras, sino que resulta perentorio iniciar un proceso amplio de reestructuración y democratización del campo que permita el acceso a la tierra y a los recursos productivos y la reorganización de la producción con el fin de abastecer los mercados internos con el máximo respeto ambiental. Es decir, hace falta ejecutar de una vez por todas algo más que una simple reforma agraria.

A partir de la década de los años noventa del siglo XX, el impulso y omnipresencia del neoliberalismo y el debilitamiento generalizado de los movimientos campesinos condujeron al Banco Mundial (BM) al liderazgo de todas las cuestiones relacionadas con la reforma agraria, pues los cambios que necesitaba el agro de los países latinoamericanos empobrecidos sólo podrían abordarse a través del mercado, es decir, mediante la consideración de la tierra, la agricultura, los alimentos o el agua como mercancías que, por lo tanto, son susceptibles de compra-venta, según la opinión de J. Vásquez (2009).

Por lo tanto, en la actualidad ya no tiene sentido hablar sólo de reforma agraria si no se incorpora a ella la necesaria soberanía alimentaria de los pueblos, pues la tierra es un bien y no una mercancía como pretende la $\mathrm{OMC}$, razonamiento defendido e impulsado por el movimiento internacional La Vía Campesina desde su fundación en Managua (Nicaragua) en 1992 y su primera conferencia celebrada en Mons (Bélgica) en mayo de 1993 (Saraigh y Sing, 2009). En los países empobrecidos en los que las desigualdades de acceso a la tierra son flagrantes, como sucede en Colombia, el modelo de reforma agraria basado en el mercado no tiene posibilidad alguna de solucionar los problemas campesinos a pesar de la insistencia del BM y el Fondo Monetario Internacional (FMI) y de sus críticas a los modelos de reforma agraria desarrollados en diferentes momentos en China, Cuba o México.

Por otro lado, las características productivas tradicionales y la clásica dependencia secular de Colombia y del conjunto de las naciones latinoamericanas en la división internacional del trabajo han llevado a estos países a un modelo mercantil netamente agroexportador. Los requerimientos de la deuda externa y la expansión del neoliberalismo desde comienzos de la década de los años noventa del siglo XX con sus políticas de mercantilismo a ultranza desembocaron en el retraimiento claro de los cultivos destinados al consumo interno y el auge de los dirigidos a la exportación y la competitividad en los mercados mundiales.

A este respecto, en el Foro Económico Mundial sobre América Latina, celebrado en Buenos Aires, en abril de 2017, uno de los debates más significativos fue la búsqueda de otras opciones económicas en la región que paliaran la dependencia de las materias primas (commodities), pues la reducción de sus precios en los mercados internacionales, fuerzan a reinventar al modelo productivo. Los años de bonanza económica gracias a los altos precios de las materias primas se han terminado, lo que ocasiona un repunte de la pobreza y la pérdida de las conquistas socioeconómicas logradas en las últimas décadas (Diario El País, Madrid, 7 de abril de 2017, p. 3). 
En cualquier caso, las consecuencias de estas tendencias no sólo se manifiestan en la reorganización de los aprovechamientos agropecuarios con el fin de responder a las nuevas exigencias, sino también en la creciente dependencia alimentaria de muchos países de la región, en la deforestación y el progresivo deterioro ambiental y en las carencias nutricionales, la miseria y el hambre de millones de seres humanos.

A esta situación en la que los cultivos comerciales sustituyen a los alimenticios no se llega sólo por medio de la consagración de la agricultura al comercio exterior, sino que en ello también tiene una influencia decisiva el proceso neoliberal de potenciación y estímulo de las grandes empresas agrarias capitalistas y de enajenación y expulsión de los pequeños agricultores familiares, cuyas producciones están orientadas básicamente a la obtención de alimentos para el abastecimiento del mercado interno. A esta situación no es ajeno, ni mucho menos, el enorme poder de influencia que tienen las exigencias productivas de la gran distribución organizada (GDO).

Esta contingencia se encuentra inmersa dentro del proceso de reformas estructurales de la economía colombiana que se pusieron en marcha, enmarcadas en un modelo netamente neoliberal, a partir de mediados de la década de los años ochenta del siglo pasado. El objetivo de estas recetas neoliberales era insertar a Colombia en la globalización. Esto suponía que el país debía convertirse en un proveedor de materias primas a nivel internacional, importando de otras economías más competitivas la mayoría de bienes, incluso alimentos básicos como los cereales. El resultado inmediato de la aplicación de estas políticas fue la desindustrialización y la crisis del aparato productivo colombiano, lo que dejó a casi un millón y medio de personas sin empleo, la superficie cultivada se redujo en 700.000 hectáreas y se comenzó a importar unos 8.000 millones de toneladas de alimentos al año. Por el contrario, se promueve la producción local de materias primas que puedan ser competitivas en los mercados internacionales: frutas, hortalizas, aceite de palma, cacao, caucho, petróleo, carbón, maderas y especies exóticas de flora y fauna. La reorientación de la economía hacia el mercado exterior ocasionó que entre el último decenio del siglo XX y los primeros años del siglo XXI las exportaciones tradicionales (café, por ejemplo) crecieran el $82 \%$ y las no tradicionales el 284\%. Dentro de estas últimas destacan las flores, donde Colombia es el segundo mayor exportador del mundo, tras los Países Bajos (Ramiro, González y Pulido, 2007: 46-47).

Por otro lado, la progresiva unificación del mercado mundial y la tendencia a la baja de los precios reales de los productos agropecuarios no parece que vayan a llevar a la agricultura campesina colombiana por el camino de las inversiones productivas ni por el del crecimiento de la productividad. Cada vez es menos capaz de invertir en equipos competitivos, ni siquiera de comprar semillas seleccionadas, abonos o pesticidas, y por ello se ve obligada a hacer duros sacrificios para renovar un mínimo las herramientas indispensables. Incluso tiene que ampliar tanto como sea posible la superficie de los cultivos destinados a la venta y reducir el espacio dedicado a los cultivos de subsistencia. Es más, el bloqueo para su desarrollo impuesto por la 
competencia de las agriculturas capitalizadas y productivas de los países ricos y el descenso paulatino de los precios agropecuarios internacionales conducen a estos campesinos mal equipados a una crisis aguda que se manifiesta en la descapitalización, el consumo precario y la escasa alimentación.

El atraso y la precariedad de la agricultura campesina aumentan sin cesar. Incluso se ve afectada por un proceso selectivo que empobrece sin remisión a los agricultores y los obliga a abandonar su hábitat y su medio de vida para engrosar la masa que emigra a las ciudades o al extranjero. Una gran parte de la responsabilidad de esta situación se debe adjudicar al progresivo despojo de la tierra a los campesinos. Lo que no puede el mercado con sus mecanismos, lo consiguen las expropiaciones forzosas, a menudo violentas, por parte de las políticas gubernamentales, las corporaciones transnacionales y los propios terratenientes locales ayudados por grupos paramilitares.

Además, la propaganda y los medios de comunicación difunden que para conseguir la modernización agrorrural es necesaria la desaparición de la agricultura campesina por ser arcaica, ineficaz e inútil para el sistema. Para ello, cualquier método es válido: los obstáculos constantes para acceder a los créditos y por consiguiente a los insumos, la expropiación de la tierra, la privatización de los recursos más productivos, la extorsión, las amenazas, las sistemáticas campañas de prensa para desprestigiar las reivindicaciones agrarias ante la opinión pública, los juicios injustos, la prisión, la criminalización de los movimientos campesinos e incluso el asesinato.

\subsection{Aprovechamientos del agro colombiano: exportación frente a consumo interno}

Según los datos del Anuario Estadístico de América Latina y el Caribe (2015) de la Comisión Económica para América Latina y el Caribe (CEPAL), la superficie cosechada de trigo era de 56.700 hectáreas en 1990 y de 4.900 en 2014. En el mismo periodo, la superficie dedicada al arroz pasa de 521.100 a 465.946 hectáreas, mientras que la de frijoles secos pasa de 164.600 a 135.451 hectáreas. Por lo que respecta al maíz, aunque se emplea mucho en la alimentación de la ganadería intensiva (cerdos y pollos de carne), también disminuye la superficie cosechada, ya que pasa de 836.000 hectáreas en 1990 a 654.093 en 2014. El único cultivo que aumenta el área cosechada es la yuca, o mandioca, que presenta 207.310 hectáreas en 1990 y 257.621 en 2014. Esto obliga a importar alimentos básicos para la población, lo que implica una pérdida notable de soberanía alimentaria.

Por el contrario, los productos que se destinan a la exportación porque complementan la demanda y el consumo de los países ricos aumentan la superficie cosechada. Los cítricos ocupan un área de 7.408 hectáreas en 1990 y de 72.140 en 2014. Algo parecido sucede con el banano, que pasa de 32.400 a 80.839 hectáreas en el mismo periodo, o con la caña de azúcar, que pasa de 318.334 a 404.499 hectáreas. Precisamente estos dos cultivos, el banano y la caña de azúcar, representan lo más 
cruel del campo colombiano, pues en algunas regiones, como es el caso del sector occidental de Urabá, se han expandido en las tierras arrebatadas a las comunidades afrocolombianas del Bajo Atrato. Estos colectivos recibieron en 1993 los títulos que los reconocían como legítimos propietarios de las tierras que habían ocupado durante generaciones. Esto no fue un obstáculo para que en 1996 más de 150.000 personas fueran expulsadas por los grupos paramilitares y los bombardeos del ejército del aire con la ya manida excusa de combatir a la guerrilla. Hasta 2003 se produjeron trece desplazamientos forzosos masivos y 115 asesinatos. En cualquier caso, en estas tierras robadas se instalaron grandes productores de banano y caña de azúcar protegidos por los militares y los servicios de seguridad privados y financiados con millones de dólares en subsidios públicos. En este año 2003 la Corte Interamericana de Derechos Humanos instó al Gobierno colombiano a que tomara medidas a favor de las comunidades desplazadas, sobre todo en lo referente al desarrollo agrícola de las tierras colectivas, predios que en la actualidad todavía no han sido restituidos a sus legítimos dueños (Guereña, 2016: 53).

Otro producto de exportación que está en auge en el campo colombiano es el aceite de palma, sobre todo debido a la fuerte demanda del sector agroindustrial. Según los datos de Fedepalma-Sistema de Información Estadística del Sector Palmero (Sispa), en 2012 se produjeron 974.000 toneladas de aceite de palma, mientras que en 2015 esta cifra fue de 1.272.522. Si se tiene en cuenta que esta producción fue de 1.109707 toneladas en 2014, sólo en un año tuvo lugar un aumento cifrado en 162.815 toneladas, es decir, casi el $15 \%$. Algo parecido a lo ocurrido en Urabá he tenido lugar en la zona oriental del país, en el departamento de Meta, con la expansión reciente de las plantaciones de palma de aceite en las tierras arrebatadas a varios grupos indígenas y de las que depende su subsistencia basada en la caza y la pesca $^{10}$ (Guereña, 2016: 53).

Pese a la tradición e importancia de la agricultura y la ganadería, la elevada disponibilidad de superficie agraria útil y las favorables condiciones climáticas, la dependencia alimenticia de Colombia es superior a la que por ejemplo muestran Estados Unidos, Canadá, Francia o los Países Bajos, y similar a la de España. La adquisición de alimentos básicos en el exterior supone un desembolso notable para una economía con muchos y graves problemas sociales. Esto demuestra de forma nítida el cambio de orientación de unos sectores agropecuarios que se dirigen a la satisfacción de la demanda de los países ricos y, por consiguiente, a la exportación, aun a costa de perder su autosuficiencia alimenticia, y lo que es peor, la posibilidad de alimentar de forma adecuada a la población. De ahí la proliferación de personas desnutridas (niños, sobre todo) y de individuos que literalmente mueren de hambre, lo

\footnotetext{
${ }^{10}$ La Unidad de Restitución de Tierras ha ordenado que se inicie el proceso para devolver los territorios usurpados a sus legítimos propietarios, pero la presencia de grupos armados han impedido hacerla efectiva. Estos grupos ya han asesinado a dos miembros de dicha Unidad.
} 
que llama la atención en un país que lucha por la apertura de los mercados agropecuarios europeos y estadounidenses.

Durante las últimas décadas, la producción agrícola y de alimentos, tanto en general como por habitante, han experimentado un importante aumento, si bien muchos de estos alimentos se destinan a la exportación. Por el contrario, ha habido un fuerte descenso en la producción de cereales, productos básicos para la alimentación humana. Asimismo, destaca el acusado incremento de los índices de producción de ganado, lo que demuestra la preeminencia que en poco tiempo ha conseguido la actividad pecuaria, sobre todo para la obtención de carne para la exportación, en el agro colombiano.

Por otro lado, existe un equilibrio relativo entre la superficie agrícola y la superficie consagrada a las praderas y pastos permanentes, hecho que por sí mismo ya indica la preferencia productiva del país, es decir, un aprovechamiento ganadero que se relaciona con la gran propiedad y el avance de la frontera agropecuaria. Aunque en términos absolutos la superficie agrícola ocupa más hectáreas, entre 1990 y 2013 ésta se reduce un $5,47 \%$, mientras que la dedicada a pastos y praderas permanentes lo hace un $4,42 \%$. Por su parte, las tierras arables, tal vez las más vinculadas a la pequeña y mediana explotación, ocupan menos superficie y se reducen un 52,07\% entre ambos años. Asimismo, el aumento es más importante en el caso de las superficies destinadas a los cultivos permanentes $(10,26 \%)$ y sobre todo por lo que respecta a las tierras en regadío $(67,7 \%)$, lo que indica un intento claro de modernización de la agricultura que practican los grandes terratenientes que tienen fácil acceso a los insumos, a la capitalización de sus predios y a los mercados exteriores. Aquí se encuadrarían los frutales, los cítricos, el banano y la palma aceitera, entre otros cultivos similares.

Se puede decir que el agro colombiano, al igual que el resto de Latinoamérica, está dominado por los llamados "cultivos flexibles" "11, que son precisamente los que demandan los mercados internacionales y los que caracterizan a unas economías eminentemente agroexportadoras. Aunque el cultivo de soja es irrelevante en Colombia, no sucede lo mismo con la caña de azúcar y la palma de aceite. La primera ocupa una superficie de más de 404.500 hectáreas $(24,12 \%$ de la superficie total cultivada) y se sitúa en segundo lugar en el conjunto latinoamericano, tras Brasil (más de 10 millones de hectáreas), mientras que la segunda se cultiva en 250.000 hectáreas

\footnotetext{
${ }^{11}$ Aquellos que tienen usos múltiples o flexibles, como es el caso de los piensos para la ganadería, los agrocombustibles y otros usos industriales y comerciales. El auge que está cobrando la adquisición de tierras en los países de América Latina por parte de compradores extranjeros, grupos financieros e incluso inversores de países de otros continentes está muy relacionado con estos cultivos flexibles. Estos compradores buscan el acaparamiento de tierras o bien tomar ventaja ante la creciente demanda actual y proyectada de alimentos. Los lugares donde se compran tierras a gran escala o son arrebatadas por la fuerza a las comunidades campesinas e indígenas de ciertas zonas suelen estar destinados a la expansión de la soja, la caña de azúcar, el maíz o la palma aceitera.
} 
(14,86\% de la superficie total cultivada) y ocupa el primer lugar de América Latina (Guereña, 2016: 35).

En definitiva, los cultivos permanentes (palma de aceite, banano, caña de azúcar, café, flores, cítricos, caucho) se han desarrollado mucho en el país debido a la financiación que los productores han recibido desde muchos centros públicos de ciencia y tecnología (Cenicafé, Cenicaña o Cenipalma). Por su parte, los cultivos no permanentes, o transitorios, como el maíz, la patata, el arroz, la yuca o las hortalizas, han retrocedido o no han aumentado tanto su superficie. Estos cultivos transitorios son fundamentales porque permiten a los agricultores sustituirlos de manera rápida según su rentabilidad cambiante, las circunstancias del mercado o las condiciones climáticas. Sería ideal que la superficie dedicada a estos cultivos no permanentes aumentara, pero no sólo para garantizar la seguridad alimentaria de la población por medio del consumo interno, sino también para orientarlos al comercio internacional, pues así se evitaría que Colombia importara el $28 \%$ de los alimentos que consume, según sostiene R. Mejía, antiguo presidente de la Sociedad de Agricultores de Colombia (SAC), ante las preguntas de la revista Semana ${ }^{12}$.

\subsection{La producción de agrocombustibles y la ganadería extensiva}

Debido a su estrecha relación con la forma habitual de proceder de la oligarquía terrateniente colombiana en connivencia con el poder del Estado, cada día es más importante la producción de agrocombustibles ${ }^{13}$ que deriva del cultivo de palma aceitera y de caña de azúcar. A este respecto, J. McMurtry (2013: 48) reflexiona y dice que:

los biocombustibles son un ciclo de alimentación mucho más grande para las empresas industriales transnacionales financiadas con fondos públicos. Sin embargo, consignas más generalizadas de 'energía verde', tranquilizan a los electores con que algo se está haciendo con la contaminación global y la desestabilización del clima. Reflexionar sobre los efectos de poner toda esa

$12<$ http://www.semana.com/economia/articulo/campo-colombiano-en-la-pobreza/438618-3>. [Consulta: 21 de abril de 2017].

${ }^{3}$ Andrés Felipe Arias fue ministro de Agricultura y Desarrollo Rural en el gobierno de Álvaro Uribe entre febrero de 2005 y febrero de 2009. Parece ser que, según José Manuel Martín Medem (2016), si Uribe no fuera candidato a la Presidencia de la República por el Partido Conservador en las próximas elecciones generales, el "uribismo" se agruparía en torno a la candidatura de Arias, gran protector y valedor de los poderosos empresarios de los biocombustibles (Martín, 2016: 264). No en vano su gestión al frente del Ministerio de Agricultura y Desarrollo Rural buscó consolidar la producción de biocombustibles en Colombia para autoabastecer al país a base de caña de azúcar y palma aceitera. Y todo ello en un momento (años 2007-2008) en el que se hacían sentir las terribles consecuencias de una aguda crisis alimentaria mundial. 
nueva demanda de tierras agrícolas a favor de los cultivos de combustible subsidiado, es algo inusual. Mientras maximice la rentabilidad para los accionistas privados con subvenciones públicas, sin correr con riego o responsabilidad en caso de fracaso, siempre será la razón por la que se les escoja.

No deja de ser paradójico que se subvencionen con fondos públicos los biocombustibles y que el Estado no intervenga para paliar las abruptas subidas de precios de los alimentos básicos que condenan a las personas al hambre, a la desnutrición y a la pérdida de sus tierras. Esta situación responde a la existencia de un modelo de negocio donde no caben consideraciones sociales, culturales o ecológicas de ningún tipo al margen del puro beneficio. Es más, esta supuesta revolución de las energías verdes es gestionada por los mismos agentes que están detrás de la crisis y que reciben financiación pública para producir los biocombustibles.

En cualquier caso, en Colombia ha habido durante el último decenio un denodado esfuerzo para defender las supuestas bondades de los biocombustibles ante la opinión pública por medio de la difusión de documentos elaborados por diversos organismos públicos (Unidad de Planeación Minero Energética, 2007; Unidad de Planeación Minero Energética, 2009; García y Calderón, 2012) y también a través de los medios de comunicación de masas ${ }^{14}$. Si bien algunas noticias recientes sostienen que el negocio de los biocombustibles ya no es tan rentable como lo era hace algunos años debido a la caída del precio del petróleo, la fuerte devaluación del peso colombiano y el cierre de la frontera con Venezuela en febrero de 2016, lo cierto es que los biocombustibles son presentados no sólo como una alternativa ambiental, sino también como una opción para impulsar el medio rural (García y Calderón, 2012: 6063) y la agricultura del país. Por supuesto, se hace mucho hincapié en los miles de empleos directos e indirectos que esta actividad genera, en la reducción de las importaciones de gasolina, en el carácter sostenible que la instancia pública le pretende conceder a esta agroindustria y en el papel vital que puede representar en esta etapa de postconflicto tras el cese de la lucha armada por parte de la guerrilla de las FARC.

La expansión de la producción de biocombustibles en Colombia responde a una política de Estado cuyo objetivo teórico es el desarrollo regional con cultivos energéticos. Para incentivar este sector, el gobierno creó exenciones tributarias, concedió subvenciones públicas y fomentó la creación de zonas francas en los terrenos donde se levantaban las plantas productoras. Ante semejantes ventajas,

http://www.semana.com/economia/articulo/biocombustibles-ya-no-son-tan-buennegocio/461232>. [Consulta: 15 de abril de 2017].

$<$ http://www.elespectador.com/noticias/economia/colombia-se-producen-biocombustiblessostenibles-articulo/344776>. [Consulta: 15 de abril de 2017].

$<$ http://www.dinero.com/pais/articulo/biodiesel-colombia/214602>. [Consulta: 15 de abril de 2017]. 
muchos inversores apostaron por este negocio, como es el caso de algunos ingenios azucareros del Valle del Caucay otros empresarios vinculados al aceite de palma.

Sin embargo, se debe tener en cuenta que la expansión de estos cultivos energéticos, sobre todo la palma de aceite, ha supuesto cambios importantes en el uso del suelo en muchos departamentos colombianos. La mayoría de las tierras dedicadas a los nuevos cultivos de palma estaban cubiertas de pastos para la ganadería extensiva a comienzos del siglo XXI. De las 106.600 hectáreas de nuevas plantaciones desarrolladas en el país entre 2002 y 2008, el 51\% reemplazaron a las tierras de pastoreo, el 14\% sustituyeron a los cultivos agrícolas y el 13,5\% relevaron a la vegetación natural de bosque y sabana (García y Calderón, 2012: 92). Aparte de los problemas ecológicos derivados de la deforestación y de la expansión del monocultivo, se debe considerar que, aunque el mayor desplazamiento de las antiguas actividades agropecuarias se ha dado en las áreas de pastoreo extensivo, no son escasas las tierras agrícolas que se han perdido al cambiar su uso, con todo lo que esto conlleva en el desarraigo del pequeño y mediano campesinado y en el riesgo de que el país acentúe su pérdida de soberanía alimentaria.

Otro aprovechamiento del agro colombiano que contribuye sobremanera a que exista una estructura de la propiedad de la tierra muy concentrada es la ganadería extensiva, fundamentalmente de vacuno. Los pastos ocupan el $80 \%$ de la superficie productiva del país (34 millones de hectáreas) pese a que sólo 15 millones de hectáreas se consideran de vocación pecuaria (Guereña, 2016: 34). Otras fuentes hablan de 39,2 millones de hectáreas utilizadas en la actualidad para la ganadería, aunque matizan que únicamente 21 millones son aptas para esta actividad. En contraste, de 21,5 millones de hectáreas de tierra con capacidad agrícola, sólo se usan 4,9 millones. Y eso que una hectárea agrícola genera 12,5 más valor que una de ganadería $^{15}$. ¿Cómo es posible semejante despropósito tan poco productivo y rentable?

Por incongruente que parezca a simple vista, Colombia ha experimentado un proceso de expansión permanente de la ganadería bovina en la frontera agropecuaria y un uso extensivo del suelo en este aprovechamiento. Según el Informe Nacional de Desarrollo Humano Colombia, elaborado por el Programa de las Naciones Unidas para el Desarrollo-PNUD (2011), en la gran mayoría de los departamentos colombianos más de la mitad de la frontera agropecuaria está ocupada por los pastos. Una razón de peso que explica este hecho es que el fenómeno de la ganadería extensiva es histórico y de alguna manera cultural, siendo estimulado por las políticas públicas y el mercado al permitir que la tierra todavía sea considerada como un bien especulativo que se acumula para obtener rentas institucionales sin mayor esfuerzo productivo. La ganadería extensiva afecta al desarrollo humano y rural porque no genera empleo, ni ingresos, ni tributos para invertir en bienes públicos. La baja tributación de estas grandes haciendas ganaderas estimula, por el contrario, la

\footnotetext{
${ }^{15}<$ http://www.semana.com/especiales/pilares-tierra/asi-es-la-colombia-rural.html $>$. [Consulta: 12 de marzo de 2017].
} 
inversión en tierras que se dedican a unas actividades extensivas y de escaso valor productivo. Además, mantiene el estado de cosas en la sociedad y en la estructura de la propiedad de la tierra, toda vez que influye de manera decisiva en la vida nacional y regional del poder político derivado de esa estructura. Incluso constituye un problema generalizado para la conservación y manejo adecuado del ambiente y de los recursos naturales de todo el país, ya que en los departamentos en los que predomina la ganadería extensiva apenas existentes bosques de uso privado en la frontera agropecuaria.

En un país donde la ganadería extensiva es omnipresente, pues los pastizales ocupan el $80 \%$ de la superficie productiva total, los principales problemas ambientales que este aprovechamiento genera es la degradación del suelo y la deforestación, sin olvidar la aceleración de la desertificación en las zonas áridas. Sin embargo, L. Palmer (2014) afirma que como consecuencia de estos hechos está surgiendo un nuevo paradigma que se basa en que la conservación de la tierra debe ir de la mano con la producción ganadera. Se trata de un ambicioso programa que se intenta aplicar en Colombia para combinar el pastoreo y la agricultura con la siembra de árboles con el objeto de posibilitar que la tierra produzca más alimentos, aumenten los ingresos de los granjeros, se recuperen los espacios degradados y se permita que el suelo cultivable sea más resistente al cambio climático. En concreto se habla de un ganadero del área del valle del río Cauca, en el suroeste del país, que durante dos décadas ha ido sustituyendo unas 89.000 hectáreas de pastoreo por árboles, arbustos y vegetación espesa, pero sin retirar el ganado vacuno. En la actualidad, sus tierras parecen más un vivero permanente que una zona de pastoreo extensivo. La madera, de gran calidad (caoba y algarrobo), crece en todo el perímetro de los pastos. Los árboles están unidos con cables eléctricos y actúan como cercas vivas. En el centro de este espacio crecen las leucaenas, árboles que son ricos en proteínas y sirven como fuente de forraje. Debajo de éstos se encuentran tres tipos de gramíneas tropicales y otros vegetales que cubren el suelo, como es el caso del cacahuete.

Este sistema agrosilvopastoril permite la denominada intensificación sostenible, ya que de manera racional y equilibrada se consiguen abundantes y diversas producciones sin dañar al ambiente, a los recursos naturales o al clima global. No es fácil que esta experiencia prospere porque, al margen de su $\operatorname{coste}^{16} \mathrm{y}$ de las complejidades técnicas que frenan su desarrollo y de las aportaciones económicas de diversas asociaciones privadas y públicas que apoyan estas iniciativas, se lucha contra la cultura y la tradición de los grandes hacendados ganaderos, propietarios acostumbrados a desarrollar una actividad, la ganadería extensiva, que históricamente se ha considerado de bajo coste y de escasa productividad. Para este tipo de hacendados siempre ha sido más importante poseer miles de hectáreas de pastizales (y miles de cabezas de ganado vacuno) como un elemento especulativo, de reserva de

\footnotetext{
${ }^{16}$ Instaurar este sistema en Colombia tiene un coste que oscila entre 1.000 y 2.000 dólares por hectárea, según la combinación de árboles y arbustos que se utilice (Palmer, 2014).
} 
valor o de prestigio social unido a un modelo político-socialtodavía imperante, que practicar una actividad rentable y productiva. La fiscalidad sobre la tierra no ha movilizado a los grandes terratenientes y hacendados para elevar la productividad de sus predios, ni tampoco para venderlos y obtener mayor rentabilidad en otras actividades. La tenencia de la tierra como bien especulativo que se acumula para obtener rentas sin ningún esfuerzo productivo y como símbolo de riqueza y prestigio social es lo que en parte explica las luchas que han asolado el país por su posesión y el fracaso de todas las reformas agrarias que se han intentado, por lo menos en el plano teórico-legal, desde la década de los años treinta del siglo XX.

\section{Conclusiones}

Dado que los grandes propietarios de tierras ejercen una fuerte influencia en las políticas públicas, o bien tienen representación en ellas, y en consecuencia se benefician de unos impuestos muy bajos, es necesario plantear la posibilidad de ceder a la Administración central la logística y el diseño del cobro de los tributos. También sería conveniente que se conformara un mecanismo de vigilancia por parte del gobierno central, consolidando así un sistema de información catastral para que los que más tienen paguen más y al mismo tiempo se consiga la flexibilización de la oferta del mercado de tierras.

Con el objeto de profundizar la democracia en el medio rural y aminorar la brecha existente entre las diferentes regiones del país, las políticas de reforma agraria y acceso a la propiedad rural, tal como ha asumido la política de restitución de tierras, debería tener como parámetro prioritario la dimensión espacial. Es bien conocido que existen focos regionales con mayores índices de concentración de la propiedad a partir de los motivos de dominación y especulación. Sería conveniente, entonces, estudiar la posibilidad de dar prioridad a estas zonas para aplicar políticas públicas, tal como indica C. A. Suescún (2013: 679-680).

Este mismo autor sostiene que el medio rural colombiano ha sido el escenario de un largo conflicto que se fundamenta en una grave injusticia: el despojo de la tierra. Las políticas de restitución de tierras, así como la asistencia técnica y financiera para las víctimas, deberían tener mayor importancia en la política pública. Aparte de representar una deuda social y política del Estado colombiano y de los actores armados (guerrilla, paramilitares, narcotraficantes), esto sería una oportunidad inmejorable para impulsar la pequeña y mediana producción. Así se reactivaría el sector agropecuario y no sólo se formalizaría la tenencia de la tierra despojada para dejarla en manos del mercado (Suescún, 2013: 680).

Cabe esperar que con las iniciativas legales tomadas sobre la tierra y su restitución a raíz de la firma de los acuerdos de paz no suceda lo mismo que en anteriores ocasiones. Todavía están frescas en la memoria esas medidas legislativas del gobierno del expresidente Álvaro Uribe que a fin de cuentas permitieron legalizar la usurpación de tierras por parte de grupos paramilitares y destinar fondos estatales para financiar proyectos productivos en dichas tierras. Muchas de estas propiedades están hoy en día 
en manos de individuos que las explotan desde el punto de vista económico. Asimismo, las políticas agrarias de Álvaro Uribe consolidan de alguna manera el despojo de la propiedad de la tierra a los campesinos. Para ello se ha utilizado como instrumento la financiación del Estado con el argumento de fortalecer la producción agroindustrial. Esto impide de hecho la restitución de sus tierras a las víctimas de la usurpación. Las iniciativas legales de Uribe se enmarcan dentro del Plan Nacional de Desarrollo (2002-2006) que luego fue ampliado al periodo 2007-2010 y que privilegia a los que considera como productos agropecuarios primordiales, es decir, los que se corresponden con los cultivos que exigen grandes capitales y son de tardío rendimiento.

Se puede decir, que en Colombia ha habido más territorio que Estado. La falta de regulaciones ha creado las condiciones idóneas para el conflicto rural con sus dos componentes: el agrario y el armado. Los protagonistas del primero son los campesinos con su lucha por la tierra (entre ellos mismos y con terratenientes e inversores), por el bienestar y por la inclusión política. Los protagonistas del segundo han sido las guerrillas, los paramilitares y los narcotraficantes, que quieren controlar los territorios, los corredores y la población. Para superar el conflicto rural, el PNUD plantea otro punto polémico: "más Estado en la sociedad y menos mercado en el Estado" (PNUD, 2011: 85). Toda vez que el mercado no ha promovido el desarrollo rural, es perentorio que el Estado intervenga para beneficio del medio rural y de toda la sociedad colombiana.

El acuerdo de paz tiene varios desafíos por delante porque si bien no entra en las cuestiones estructurales del problema, al menos debería llegar a un punto de decencia, con un horizonte de justicia social, económica y ambiental, garantizando los derechos de los campesinos a una vida digna. Así lo solicita la Misión Internacional de Solidaridad con Colombia, conformada por 16 países de Latinoamérica, África y Europa y desarrollada entre el 20 y el 24 de septiembre de 2016 en varios lugares del país por medio de audiencias públicas: Putumayo, Norte de Santander, Cauca, Meta, Magdalena y Antioquia. Esta misión se organizó en los momentos previos a la firma del acuerdo de paz entre el Estado colombiano y las FARC y fue promovida por La Vía Campesina Internacional y la Coordinadora Latinoamericana de Organizaciones del Campo ${ }^{17}$. Su principal objetivo fue el apoyo al cumplimento de los acuerdos de La Habana, con especial vigilancia en el primer punto de la Reforma Agraria Integral, que consiste en una serie de transformaciones para democratizar el acceso a la tierra en los campos de Colombia. También se tuvieron en consideración otros puntos relacionados con la apertura democrática, el fin del conflicto, la solución al problema de las drogas ilícitasy las víctimas de la lucha armada. En definitiva, no sería exagerado afirmar que es desde el campo donde se construye y se vive la paz.

\footnotetext{
${ }^{17}<$ https://viacampesina.org/es/index.php/temas-principales-mainmenu-27/derechos-humanosmainmenu-40/2777-la-paz-se-construye-en-el-campo-mision-internacional-de-solidaridadcon-colombia>. [Consulta: 2 de abril de 2017].
} 
Por estos motivos es urgente organizar una política integral de tierras. La restitución y formalización son una parte muy importante, pero hay que ir más allá, hacia una política que se atreva a intervenir en la estructura agraria y que modifique la alta desigualdad en la propiedad de la tierra. Esto incluye, por supuesto, la ejecución de políticas sobre el agua y el ambiente. Se debe eliminar también la especulación con la tierra, dejar de tener propiedades agrarias simplemente para valorizarlas, sin hacerlas producir con eficiencia y rentabilidad.

En palabras de V. A. Vargas Rivera (2007), las exigencias más claras de las organizaciones campesinas de Colombia son las siguientes: redistribuir el latifundio, cerrar la frontera agrícola, dar un uso técnico al suelo, reubicar a los colonos asentados en áreas frágiles, acabar con los cultivos de uso ilícito, incentivar y proteger la economía campesina y agropecuaria de acuerdo con los intereses de la nación, lograr una producción limpia de productos químicos e incrementar la organización social y empresarial de las comunidades rurales para conseguir una verdadera participación, exigiendo junto a todo esto la salida política al conflicto armado y el respeto a todos sus derechos constitucionales. Asimismo, los campesinos exigen el establecimiento de cientos de las denominadas Zonas de Reserva Campesina (ZRC), áreas de colonización en las que se fomenten y estabilicen las economías campesinas con el objeto de controlar la expansión de la frontera agropecuaria y conseguir una mayor participación de las comunidades rurales. No hay que olvidar que cuando la agricultura apenas permite sobrevivir la frontera agropecuaria se extiende, ocupando para la agricultura y la ganadería extensiva zonas muy frágiles desde el punto de vista ambiental y con un gran riesgo de padecer calamidades naturales.

Por su parte, las elites poderosas han luchado contra el impuesto que grava la propiedad de la tierra por medio de su influencia en las autoridades municipales. Se produce una relación dialéctica en la que por medio de un conflicto social y armado, que se ha prolongado durante más de cincuenta años, la elite defiende su poder económico y político poniendo en riesgo los derechos fundamentales de los campesinos: económicos, sociales, culturales y ambientales.

El Estado debería expropiar, aquellas tierras improductivas alegando su mal uso, pues esto perjudica al bien común, a la sociedad en su conjunto. La pregunta es si Colombia está dispuesta a hacerlo. O mejor, el interrogante más acertado sería saber si los poderes fácticos tradicionales van a permitir que Colombia lo haga. La nueva Ley de Víctimas y Restitución de Tierras es limitada y bastante incompleta y, además, no parece fácil que el Estado tenga capacidad para responder a las exigencias que demanda su ejecución real, entre otras razones porque algunos partidos políticos y parte de la sociedad colombiana se muestran renuentes a aceptar un cambio profundo en la estructura agropecuaria, a alterar lo que ellos llaman el derecho a la legítima propiedad de la tierra o a un aumento significativo de los impuestos que deberían satisfacer los grandes terratenientes. Así se comprueba en el documento Bases para 
un Acuerdo Nacional de Paz presentado el 12 de octubre de 2016 por el Centro Democrático, conservador y liberal partido del expresidente Álvaro Uribe ${ }^{18}$.

\section{Bibliografía}

Asistencia Técnica Internacional del Tercer Laboratorio de Paz (2011): Campesinos, tierra y desarrollo rural. Reflexiones desde la experiencia del Tercer Laboratorio de Paz. Bogotá. Disponible en:

$<\mathrm{http} / / /$ ecas.europa.eu/archives/delegations/colombia/documents/projects/cartilla_tierra_y_des arrollo_lab_paz_iii_es.pdf $>$. [Consulta: 9 de febrero de 2017].

Díaz Callejas, A. (2002): Colombia: la reforma agraria y sus documentos fundamentales. Cartagena de Indias, Universidad de Cartagena.

Escobar, G. (2016): Estructura y tenencia de la tierra agrícola en América Latina y el Caribe. Buenos Aires, Nueva Sociedad/Fundación Friedrich Ebert, marzo, 1-7.

Fals Borda, O. (1979): Historia de la cuestión agraria en Colombia. Bogotá, Punta de Lanza.

FAO (2016): El estado mundial de la agricultura y la alimentación. Cambio climático, agricultura y seguridad alimentaria. Roma. Disponible en: <http://www.fao.org/3/ai6030s.pdf $>$. [Consulta: 12 de abril de 2017].

FAO-CEGA (1994): El mercado de tierras y la formación de propietarios en Colombia: estudio de casos. Roma.

Fernández Castillo, S. (2001): Una 'modernización' con campesinos. Una globalización incluyente. $8^{\circ}$ Encuentro de Geógrafos de América Latina. Santiago de Chile, marzo.

García, A. (1970): Reforma agraria en América Latina. Buenos Aires, Juárez.

García Romero, H. y Calderón Etter, L. (2012): Evaluación de la política de Biocombustibles en Colombia. Bogotá, Fundación para la Educación Superior y el Desarrollo (Fedesarrollo). Disponible en: <http://www.fedesarrollo.org.co/wp-content/uploads/2011/08/Evaluaciónde-la-politica-de-Biocombustibles-en-Colombia.pdf $>$. [Consulta: 7 de abril de 2017].

Guereña, A. (2016): Desterrados: tierra, poder y desigualdad en América Latina. Oxford (Reino Unido), Oxfam. en: $<$ https://www.oxfam.org/sites/www.oxfam.org/files/file_attachments/desterrados-full-es29nov-web_0.pdf>. [Consulta: 8 de febrero de 2017].

Guimarães, A. P. (1979): A crise agraria. Rio de Janeiro. Paz e Terra.

Instituto Geográfico "Agustín Codazzi” (IGAC) (2012): Atlas de la distribución de la propiedad rural en Colombia. Bogotá, IGAC.

Lorente Sánchez-Bravo, L. (1984): Distribución de la propiedad rural en Colombia, 19601984. Bogotá, Ministerio de Agricultura-CEGA.

Machado Cartagena, A. (1998): La cuestión agraria en Colombia a finales del milenio. Bogotá, El Áncora Editores.

$18<\mathrm{http}$ //www.centrodemocratico.com/?q=articulo/documento-bases-de-un-acuerdo-nacionalde-paz $>$. [Consulta: 6 de febrero de 2017]. 
Martín Medem, J. M. (2016): Colombia feroz. Del terrorismo de Estado a la negociación con las FARC. Madrid, Los Libros de la Catarata.

Martínez, M. (1938): Régimen de tierras en Colombia. Bogotá,Talleres Gráficos Mundo al Día.

McMurtry, J. (2013): La fase cancerígena del capitalismo. De la crisis a la cura. Valencia, Tirant Humanidades.

Mendieta y Muñoz, L. (1960): La propiedad de la tierra. Economía Grancolombiana, 5, 14, 268-327.

Mendoza Pérez, D. (1942): Estudio sobre la tenencia de la tierra. Revista de la Academia Colombiana de Jurisprudencia, XVI, 145-146, diciembre.

OCDE (2015): Revisión de la OCDE de las Políticas Agrícolas: Colombia 2015. Evaluación y Recomendaciones de Política. Bogotá: OCDE Colombia. Disponible en: $<$ https://www.oecd.org/countries/colombia/OECD-Review-Agriculture-Colombia-2015Spanish-Summary.pdf $>$. [Consulta: 30 de enero de 2017].

Offstein, N. (2005): Distribución de la tierra rural agrícola al nivel nacional, departamental y municipal en Colombia: un análisis de la maraña de pobreza, desigualdad y violencia. Documento del Centro de Estudios sobre Desarrollo Económico (CEDE). Bogotá, Facultad de Economía. Universidad de los Andes.

Palmer, L. (2014): En los pastos colombianos coexisten vacas, cultivos y madera. Yale Environment 360. Traducción de Universia. New Haven, Yale School of Forestry \&Environmental Studies. .Disponible en: <http://e360yale.universia.net/en-los-pastoscolombianos-coexisten-vacas-cultivos-y-madera $>$. [Consulta: 9 de abril de 2017].

Pérez Ramírez, G. (1959): El campesinado colombiano: un problema de estructura. Bogotá, Iqueima.

Piña Cano, M. (2001): La globalización y su impacto regional en el agro latinoamericano. En Perales Salvador, A., Del Valle Sánchez, M. y Morales Morales, B. (Comp.): Integración Regional y Globalización. México DF, Departamento de Sociología Rural y Grupo de Investigación en Economía, Comercio y Administración, Universidad Autónoma Chapingo, 248-259.

Programa de las Naciones Unidas para el Desarrollo (PNUD) (2011): Colombia rural. Razones para la esperanza. Informe Nacional de Desarrollo Humano Colombia 2011. Bogotá. Disponible en: $<$ http://www.undp.org/content/dam/colombia/docs/DesarrolloHumano/undp-coic_indh2011-parte1-2011.pdf>. [Consulta: 9 de abril de 2017].

Ramiro, P., González, E. y Pulido, A. (2007): La energía que apaga Colombia. Los impactos de las inversiones de Repsol y Unión Fenosa. Barcelona, Icaria.

Reyes Posada, A. (1988): Conflictos agrarios y luchas armadas en la Colombia contemporánea: una visión geográfica. Análisis Político, 5, 6-27.

Robledo, J. E. (2005): Agricultura, educación y comercio. El botín neoliberal. CaliBucaramanga-Bogotá, Fundación para la Investigación y la Cultura.

Saraigh, H. y Sing, Y. (2009): La Vía Campesina pide que la agricultura sea retirada en su totalidad del ámbito de la OMC. Rebelión, 8 de septiembre. Disponible en: $<$ http://www.rebelion.org/noticia.php?id=91100>. [Consulta: 18 de octubre de 2009]. 
Sarmiento, E. (2015): El abandono agrícola. Diario El Espectador. Bogotá, 9 de diciembre. Disponible en: $\quad<$ http://www.elespectador.com/opinion/el-abandono-agricola-0 $>$. [Consulta: 2 de enero de 2017].

Segrelles Serrano, J. A. y Vásquez Sánchez, J. (Coord.) (2012): Multifuncionalidad rural y nueva ruralidad. La experiencia europea y la potencialidad de Colombia. Madrid: Ministerio de Agricultura, Alimentación y Medio Ambiente.

Suescún Barón, C. A. (2013): La inercia de la estructura agraria en Colombia: determinantes recientes de la concentración de la tierra mediante un enfoque espacial. Cuadernos de Economía, 32 (61), 653-682.

Tanuro, D. (2011): El imposible capitalismo verde. Del vuelco climático capitalista a la alternativa ecosocialista. Torrejón de Ardoz (Madrid), La Oveja Roja.

Unidad de Planeación Minero Energética (UPME) (2007): Desarrollo y consolidación del mercado de biocombustibles en Colombia. Bogotá. Disponible en: $<$ http://www.upme.gov.co/Upme12/2007/Upme13/Mercado\%20de\%20Biocombustibles.p df $>$. [Consulta: 8 de abril de 2017].

Unidad de Planeación Minero Energética (UPME) (2009): Biocombustibles en Colombia. Bogotá. Disponible en: <http://www.upme.gov.co/docs/biocombustibles_colombia.pdf $>$. [Consulta: 7 de abril de 2017].

Unidad de Planificación Rural Agropecuaria (UPRA) (2015): Proyectos - Distribución de la propiedad rural. Bogotá. Disponible en: $<$ http://www.upra.gov.co/documents/10184/23342/Proyectos+Distribución+de+la+Propied ad+de+la+propiedad.pdf/d78e382c-4d60-9cfd-da42fb5be8b9>. [Consulta: 30 de enero de 2017].

Vargas Rivera, V. A. (2007): La tenencia de la tierra: un problema en Colombia. Bogotá, Agencia Prensa Rural, 7 de diciembre. Disponible en: $<$ http://presnarural.org/spip/spip.php?article1288>. [Consulta: 22 de marzo de 2017].

Vásquez Sánchez, J. (2003): El ordenamiento territorial y el proceso de paz en Colombia. Revista Comercio Exterior, 52, 2, 170-183.

Zulueta, E. (1973): La tierra en Colombia. Cuadernos La Oveja Negra, 6. Medellín, La Oveja Negra. Disponible en: <https://es.scribd.com/document/184046558/Estanislao-Zuleta-LaTierra-en-Colombia $>$. [Consulta: 10 de marzo de 2017]. 